УДК 5519.1379.85

https://doi.org/10.36906/FKS-2021/52

Козырев А.Н.

Саратовский военный ордена Жукова Краснознаменный институт войск национальной гвардии РФ,

2. Саратов, Россия;

Евсиков С.A.

Михайловская военная артиллерийская академия,

г. Санкт-Петербург, Россия

\title{
СОВРЕМЕННЫЕ ПРОБЛЕМЫ И ПЕРСПЕКТИВЫ РЕКРЕАЦИИ
}

Аннотация. В статье представлены результаты проведенного исследования по выявлению современных проблем в сфере рекреации населения России. В том числе затронуты проблемы частного характера сферы рекреации: кадрового состава, рекреации детей, финансовые проблемы и проблемы, связанные с арендой лесных участков. Полученные результаты дают возможность говорить о перспективном направлении в рекреационной сфере.

Ключевые слова: рекреация, туризм, финансирование, спортивные объекты, отдых.

Kozyrev A.N.

Saratov Military Order of Zhukov Red Banner Institute of the National Guard Troops of the Russian Federation

Saratov, Russia;

Evsikov S.A.

Mikhailovskaya Military Artillery Academy,

St. Petersburg, Russia

\section{MODERN PROBLEMS AND PROSPECTS OF RECREATION}

Annotation. The article presents the results of the conducted research on the identification of modern problems in the field of recreation of the Russian population. In particular, problems of a private nature in the field of recreation were touched upon: personnel, recreation of children, financial problems and problems related to the lease of forest plots. The results obtained make it possible to talk about a promising direction in the recreational sphere.

Keywords: recreation, tourism, financing, sports facilities, recreation.

На современном этапе по данным статистики каждый пятый житель нашей планеты является участником сферы рекреации, выступая там либо в качестве обслуживающего персонала, либо в качестве туриста [8, с. 33]. Сфера рекреации необходима для развития всестороннего воспитания молодого поколения. А работа по улучшению этой сферы, ее нормативного обеспечения требует качественной подготовки сотрудников сферы рекреации. Кроме этого, актуальность настоящего исследования обусловлена значимостью рекреационной сферы для экономики России, а также для сферы медицинского обслуживания и социальной сферы. И, хотя на сегодня, сфера рекреации пока занимает небольшое место среди услуг туризма, но потребность в услугах рекреации с каждым годом растет из-за роста проблем с экологией, негативно сказывающихся на здоровье человека. Возникает нужда в санаторно-курортном отдыхе. Поэтому улучшение санаторно-курортного отдыха и сферы 
рекреации становится одним из приоритетных направлений развития туризма. И на это оказывает влияние не только необходимость в создании человеку условий для естественного поддержания его здоровья, но и тот факт, что туризм становится одним из источников улучшения финансового благосостояния Российской Федерации. Кроме этого, в сфере туризма становится задействовано все большее количество людей, что влияет на улучшение состояния рынка рабочей силы в РФ.

Все это обуславливает актуальность исследуемой проблемы и внимание государства к проблемам рекреации. Изучение рекреационной сферы позволило нам выделить существующие проблемы в ней. Первой проблемой является проблема разрыва между ростом на услуги туризма и возможностью предоставления рекреационных ресурсов. Сложившиеся ранее методы организации рекреации сегодня уже не отвечают современному уровню общественного прогресса из-за возросших критериев потребителей к насыщенности отдыха. Они желают получать много впечатлений и информации от экскурсий, анимации и других мероприятий.

Другой проблемой можно назвать проблему рекреационного отдыха детей, заключающуюся в необходимости создания им разнообразных форм отдыха, которые бы способствовали формированию у них моральных и этических норм, оздоровления детей, их развития и обучения. Эффективное решение такой проблемы видится в привлечении частного капитала по схеме государственно-частного партнерства [4, с. 167].

Проблема рекреации проявляется и в недостаточной обеспеченности спортивными сооружениями населения страны. А.Н. Яковлев приводит пример показателя обеспеченности спортивными сооружениями в $22-30 \%$ от социальной нормы) [10, с. 277]. Также зачастую имеющаяся в наличии спортивная база используется неэффективно. Проблемным остается и доступ к развитой спортивной инфраструктуре.

3.Н. Зевреева выделяет также такие проблемы в сфере рекреации, как: отсутствие либо уменьшение бюджетных мест на заочной форме обучения по туризму, отсутствие «точки роста» активных видов внутреннего туризма, многовекторность обучения специалистов по туризму [5, с. 50].

Белохвостова Н.В. выделяет проблему необходимости финансовой поддержки со стороны государства туризма для его развития. Ее необходимость обусловлена нуждающейся в обновлении материально-технической базой, результатом чего становится неэффективность или низкая эффективность от деятельности государственных предприятий сферы рекреации: санаториев, пансионатов [2].

Вытекающей проблемой данного сектора становится низкая активность инвесторов. Подобное отсутствие внимания со стороны инвестирующих компаний и организаций вызвано не только фактором риска и сложностью его оценки для этой отрасли, но и длительностью периода окупаемости вложений, а также тем фактом, что большая часть предприятий санаторно-курортного направления еще остались в государственном управлении. Среди них практически нет конкурирующих факторов, что отрицательно действует на возможность их экономического развития. В то же время действующие на основе коммерции санатории представлены в малом количестве.

Кроме того, зачастую пансионаты и санатории располагаются достаточно близко к территориям, которые особо охраняются государством. Это становится еще одним фактором, который сдерживает их развитие, ведь для того, чтобы инвестировать свои средства в данные финансовые объекты, иностранные компании должны проходить сложную процедуру оформления разного рода документов, включая договора аренды и лицензии разного порядка. В дополнение к этому сложность инвестирования данных объектов зависит и от 
необходимости восстановления их инфраструктуры. Это делает неопределенным количество средств, которые понадобятся для инвестиций в данный рекреационный объект, и, соответственно, возникает вопрос о сроках окупаемости такого инвестирования. Следствием выше обозначенных нюансов является отсутствие внимания инвесторов к таким объектам.

Проблема состоит и в том, что всей отрасли рекреации требуется реструктуризация и модернизация. Материально-техническая база санаториев и курортов находится на низком уровне. Их износ часто выше $80 \%$. Рынок услуг рекреации зачастую не адекватен. Это выражается в свойствах экономического поведения субъектов, действующих на нем.

Во-первых, люди редко изменяют свое поведение в сфере рекреации, т.е. можно сказать об отсутствии динамики со стороны потребителей рекреационных услуг.

Во-вторых, на экономическое поведение действующих на этом рынке субъектов оказывают влияние природные факторы: наличие в регионе природных ресурсов и место расположения санатория.

В-третьих, предложение на рынке рекреации является локальным, поскольку зависит от местности, где находится субъект, предлагающий услуги на рынке рекреации. Такие субъекты не обладают мобильностью относительно рынка.

В-четвертых, клиент, заказавший услугу рекреации, зачастую не знает, какого качества услуг он в итоге получит, поскольку информация о таких услугах противоречива. Последнее диктует необходимость государственного регулирования данного рынка услуг.

Следствием этого Бекетов Н.В. считает необходимым введение нормативов по рекреационным услугам и гарантий по их соблюдению [3].

Кроме того, по его мнению, государственное регулирование данной сферы нужно из-за того, что в ней потребляются разного рода общественные блага: лесопарки, скверы, горы и др. Нужда в государственном регулировании данной сферы вызывает вопрос об обозначении границ сферы государственного регулирования. Эти границы зависят от проводимой государством социальной политики, которая имеет своей целью поддержку населения страны и повышение их качества жизни и благосостояния, а также уменьшение разницы между беднейшими и богатыми слоями населения, повышение степени доступности благ социального порядка для граждан. Проблемой рекреационной сферы также можно назвать и проблему утилизации бытовых отходов социума, которые не всегда способна утилизировать природная среда таким образом, чтобы остаться в сбалансированном экологическом состоянии. Особенно это относится к водной и лесной среде, в которой любят отдыхать большинство населения. С этой проблемой тесно связана и проблема аренды лесов. Получение лесного участка в аренду на длительный срок создает иллюзию собственности у арендаторов. Это приводит к установке заборов у границ арендованных участков, что исключает возможность воспользоваться прогулкой по лесу населению [8, с. 34].

Кроме этого, существует проблема подготовки кадров в сфере рекреации [7, с. 27]. Необходимо качественное обслуживание потребителей услуг туризма и рекреации. Поэтому задачи, которые стоят сегодня перед сферой рекреации, можно обозначить следующим образом: создание многоступенчатой и непрерывной системы подготовки и переподготовки кадров, улучшение информационно-аналитического сопровождения инфраструктуры сферы рекреации и создание типовой системы менеджмента качества организаций сферы рекреации $[9$, c. 88$]$.

В сфере рекреации имеется и еще ряд проблем. Так, во многих регионах (в том числе в Тамбовском) плохая коммунальная инфраструктура [6, с. 441]. В других регионах может наблюдаться и ее отсутствие. Нет подъездных дорог, стоянок для автомобилей, мест общего пользования водоснабжением, санитарных мест пользования, отсутствие береговых 
ограждений, табличек и др. Кроме того, зачастую на сайтах администрации регионов отсутствует информация по вопросам коммунально-инфраструктурного обеспечения зон рекреации. Отсюда вытекают проблемы управления объектами рекреации и их финансового обеспечения.

На региональном уровне чаще всего необходимым является создание списка объектов рекреации регионального значения, которые нуждаются в коммунально-инфраструктурном обеспечении, разработке законодательных основ. Также необходимо включение многих объектов рекреации в целевые программы по развитию коммунальной инфраструктуры в традиционных местах рекреации и финансирование их [6, с. 441].

Перспективами развития рекреации мы видим привлечение иностранного капитала в сферу рекреации [1, с. 123]. Для этого необходимо создать ему нормативные условия, которые обеспечивали бы ему экономическую и правовую стабильность. Земля должна быть включена в реальный экономический оборот. На этой основе должны проводиться разработки взаимовыгодных инвестиционных проектов с иностранными организациями и финансирование целевых программ в рекреационной сфере.

\section{Литература}

1. Балкарова 3.М. Некоторые проблемы развития финансовой базы индустрии рекреации // Известия Кабардино-Балкарского научного центра РАН. 2014. № 6. С. 123-127.

2. Белохвостова Н.В. Общие проблемы региональных рекреационных комплексов и пути решения // Науковедение. 2017. Т. 9. № 3.

3. Бекетов Н.В. Проблемы развития рынка рекреационных услуг // Вестник ассоциации вузов туризма и сервиса. 2008. № 2.

4. Боголюбов В.С., Боголюбова С.А. Инновационное решение развития проблем рекреации и туризма // Россия и Санкт-Петербург: экономика и образование в XXI веке: научная сессия профессорско-преподавательского состава, научных сотрудников и аспирантов по итогам НИР за 2015 год: сборник лучших докладов. 2016. С. 167-169.

5. Зевреева 3.Н. Проблемы развития физкультурного образования, спортивнооздоровительного туризма и рекреации в Республике Крым // Проблемы физической культуры, спорта и туризма в свете современных исследований и социальных процессов: сборник трудов Международной научно-практической конференции. 2017. С. 50-54.

6. Кузнецов И.А. Проблемы обеспечения коммунальной инфраструктурой зон рекреации и туристских объектов в региональной экономике // Саяпинские чтения. 2019. С. 441-448.

7. Павлов Е.А. Проблемы законодательного регулирования подготовки, переподготовки и повышения квалификации кадров для сфере рекреации и спортивно-оздоровительного туризма // Вестник ассоциации вузов туризма и сервиса. 2016. Т. 10. № 1. С. 27-37.

8. Помазнюк В.А., Латыпова Л.В. Проблемы рекреации городских лесов // Леса России и хозяйство в них. 2013. № 1. С. 33-34.

9. Проблемы и перспективы развития туризма, рекреации и фитнеса: материалы межкафедральной конференции РГУФКСМиТ 28-29 марта 2016 г. РГУФКСМиТ, 2016. 262 с.

10. Яковлев А.Н., Макарова Л.С. Физическая рекреация, лечебно-оздоровительный и медицинский туризм: проблемы, перспективы // Устойчивое развитие экономики: состояние, проблемы, перспективы: Сборник трудов XI международной научно-практической конференции. 2017. С. 277-279.

(C) Козырев А.Н., Евсиков С.А., 2021 